\title{
Laura Restrepo, Silvia Galvis, Pilar Quintana y Ma. Cristina Restrepo: vectores de lectura en la (narco)novela colombiana actual* Laura Restrepo, Silvia Galvis, Pilar Quintana and
} Ma. Cristina Restrepo: Vectors of Reading in the Colombian Contemporary (Narc)Novel

\author{
Juan Alberto Blanco Puentes \\ Pontificia Universidad Javeriana \\ blanco.juan@javeriana.edu.co
}

\begin{abstract}
Existe un grupo de novelistas que con voz propia caracterizan; desde lo ficcional y lo real, personajes propensos a la negación de los espacios citadinos construidos desde lo histórico, lo literario y lo sociológico, más que desde lo económico. Y en este sentido, su escritura se convierte en referente, pues desarrollan una nueva forma de acceder a la ciudad, sus personajes y los sucesos de fines, del siglo XX y comienzos del siglo XXI que desde lo económico, lo político y lo social generaron una implosión determinista de Bogotá, Cali y Medellín y por extensión de todo el país. A ese grupo pertenecen las escritoras colombianas Laura Restrepo, Silvia Galvis, Pilar Quintana y Ma. Cristina Restrepo, cuyas novelas establecen las coordenadas narrativas de una escritura más allá de la sensibilidad con la que sitúan de manifiesto los vectores de una mirada acuciosa de una sociedad comprometida con la historia y las expresiones de su propia existencia.
\end{abstract}

Palabras clave: Literatura colombiana, escritura y mujer, novela social, novela del narcotráfico, visión de mundo.

There is a group of novelists whose own voice characterizes from the fictional and the real a series of characters prone to the negation of the city spaces built from the historical, the literary and the sociological, rather than from the economic. And in this sense, their writing becomes a reference, because they develop a new way of accessing the city, its characters and the events of the late twentieth and early twenty-first century that, from the economic, political and social generated a deterministic implosion of Bogotá, Cali and Medellín and by extension of the whole country. This group includes the Colombian writers Laura Restrepo, Silvia Galvis, Pilar Quintana and Ma. Cristina Restrepo, whose novels establish the narrative coordinates of a writing beyond sensibility, with which the vectors of a diligent look of a society committed to history and the expressions of its own existence.

Key words: Colombian literature, write and woman, social novel, narcotraffic's novel, vision of the word.

\footnotetext{
* Una primera versión de este artículo se presentó en el $V$ Coloquio Nacional de Historia de la Literatura Colombiana. Mujeres y Literatura: aportes y perspectivas en el ámbito internacional. U de Antioquia. Medellín, octubre 26-28 de 2011.
} 


\section{Introducción}

La literatura permite convertir la palabra en eco de la memoria individual o colectiva; en atención a ello, la producción literaria colombiana ha dejado atrás el realismo mágico, ese "hallazgo crítico-interpretativo que cubría de un golpe la complejidad temática (que era realista de un modo distinto) de la nueva novela y la necesidad de explicar el pasaje de la estética realistanaturalista a la nueva visión ("mágica") de la realidad" (Chiampi, 1983: 21), y ha dado paso a una "inversión" de acciones-temas que han convertido las circunstancias sociales de un país real, en la fuente de una nueva literatura. Escritoras que con sus voces trazan el color del silencio. Personajes traídos de la realidad conviven entre sucesos que inspiran la escritura que tiene como objeto la trascendencia de la historia desde la palabra escrita.

El realismo mágico se convirtió en realismo trágico, pues a fines de la década del setenta y comienzos de la década del 80 surgió en el escenario de la historia de Colombia un fenómeno tan devastador, pero tan negado en su existencia, que parecería que no tendría fin: el narcotráfico. Muchos años después, frente a "los pelotones de fusilamiento", el gran capo caería entre el cielo y la tierra de su patria chica, y todos sonrieron frente a las cámaras de la prensa (propia y extraña), pues el final de una guerra llegaba. Una situación no más alejada de la realidad, pues solo fue el reconocimiento de las debilidades de un Estado Ficcional y de su alianza con los enemigos personales del capo y de esta forma determinar una nueva etapa del narcotráfico en el país, hoy ya recreado en los titulares de la prensa internacional con una nueva atmósfera.

En este escenario histórico narrativo es que aparecen Laura Restrepo (Bogotá, 1950), Silvia Galvis (Bucaramanga, 1945-Bogotá, 2009), Pilar Quintana (Cali, 1972) y Ma. Cristina Restrepo (1949), cuyas novelas, Delirio (2004), La mujer que sabía demasiado (2006), Coleccionistas de polvos raros (2007) y La mujer de los sueños rotos (2009), respectivamente, y objeto de este escrito, se enmarcan dentro de "la novelística contemporánea colombiana de temas relacionados con la violencia y el narcotráfico y ahonda[n] en los asuntos que se refieren a la preservación de la memoria individual y colectiva de la nación" (Sánchez-Blake y Lirot, 16).

\section{Delirio: de la enfermedad individual a la colectivización del mal}

La novela de Laura Restrepo ${ }^{1}$ cuenta la historia de cómo recuperar la razón perdida de Agustina, anagrama de Angustia, con la ayuda de su esposo Aguilar, con el apoyo directo e indirecto de los familiares, quienes representan

\footnotetext{
1 Laura Restrepo también aborda el tema del narcotráfico (en la periferia del país) en la novela Leopardo al sol (1989), con la que se abre el paréntesis del tema que se cierra con Delirio, y que da cuenta del origen primigenio del narcotráfico, que vino a vitalizar las rutas del contrabando que proliferaban en el país. El escenario es La Guajira y los personajes se enfrascarán en una lucha fratricida por mantener una herencia de sangre tribal, a la vez que determina los dos caminos a seguir en pro de una economía rebosante: el contrabando de cigarrillos o el tráfico de drogas. Se suma a ello un elemento disgregador: el sicario, sujetoelemento con el que se rompe la tradición heredada y se genera el "apocalipsis" en la novela.
} 
una sociedad que sucumbió en la ilusión del dinero fácil, en un momento en el que comienzan a hacer negocios con el capo de todos los capos, con la esperanza puesta en que así podrán conservar el estatus socioeconómico adquirido a través de la tenencia de tierras. Espacios que se fueron convirtiendo en lugares de descanso y del recuerdo, pues la economía se sostiene ahora en el dinero que se obtiene gracias al narcotráfico.

En su novela, Laura Restrepo teje en tres tiempos narrativos la forma cómo la clase pudiente bogotana ingresó, enceguecida por el dinero fácil, en el lavado de dinero, con un socio por todos conocidos, pero negado en su propia voz. En esta ocasión, la fábula gira en torno a la familia Londoño. Delirio es una historia de amor que se muestra más sólida que los demás valores de la sociedad colombiana y cuyo final terminó siendo la orfandad como herencia social, pues la figura paterna que reafirmaba su poder económico desaparece. La nación que otrora cimentó su riqueza en la tenencia de tierras, que poco a poco fueron desapareciendo, es la realidad palpable de su advenimiento en una falsa apariencia, de ahí que "las haciendas productivas de tu abuelo Londoño hoy no son más que paisaje" (Delirio: 80 ).

Escenario narrativo que le permite al Midas lograr sus dos objetivos: pertenecer a la clase pudiente de Bogotá y tener dinero para sostener la apariencia en que vive, de ahí que su táctica sea el lavado de dinero y su estrategia establecer el vínculo por dinero entre Pablo Escobar y tanto los Londoño como toda familia que quisiera convertir, por obra y gracia del Midas, sus pesos en dólares. Este aspecto va generando una especie de igualdad social, pues todos buscaron lucrarse de alguna forma de la oferta y la demanda que implicaba la producción de cocaína, hecho que da cuenta de la existencia de "una economía política del postmodernismo [que] debe rendir cuenta del consumo especializado, las sobrecargas de la demanda y el consumo e identidad colectiva" (Mejía, 2009: 106).

El aspecto social que subyace en la novela está referido además de Agustina, en los personajes de la Araña Salazar (socio del Polo Club de Las Lomas), José Luis Eyerbe (el Paraco), Rony Silver (el 007, el Informante), por un lado; y por el otro, Aguilar, Martha Helena, Toño y Carlos, sus hijos, y en medio de los dos está, por supuesto, McAlister. Estos dos grupos se sitúan en vectores geográficos distintos y distantes, pues se sabe que "del norte al sur de Bogotá hay más distancia que de aquí a Miami" (Delirio: 126).

Poco a poco la novela de Restrepo va configurando un concepto de nación, de tal manera que logramos visualizar la herencia que nos dejaron los personajes: cada una de sus voces se convierte en "réplica y contrarréplica de las otras. No es un discurso antagonista, es el verbo al servicio de la escritura. [ ], pues Laura Restrepo habla desde el personaje, escucha y enlaza los diversos eslabones que conforman la cadena narrativa de una nación construida y nutrida desde la realidad" (Blanco, 2007: 305).

Todo ello a expensas de la memoria colectiva que tiende a particularizarse desde la palabra; sin embargo, llegamos a descubrir que la memoria termina por "convocar fantasmas. Los sufrimientos de los otros pueden sangrar en el alma propia. Se busca la protección. La memoria es inventiva. 
La memoria es una puesta en escena. La memoria se invita a sí misma y es difícil alejarla" (Sontag, 2007: 44). Quizás sea la razón para que el mundo y quienes rodean al Midas McAlister solo sean "actores y escenarios de una obra que ya terminó, y vinieron los utileros y alzaron con todo y ya cayó el telón" (Delirio: 327), de la ciudad.

Bogotá aparece como la ciudad-mapa, pues los topónimos se suceden como lugares específicos a medida que la narración ocurre; asimismo, los vectores que conducen de un lugar a otro son bien referenciados entre los dos grandes sectores urbanos: el Norte y el Sur. La escritura al servicio de una cartografía convertida por medio de los sentidos en aprendizaje del fenómeno de violencia que vive el país. Una ciudad-bélica del todos contra todos (Delirio: 24), cuyos puntos cardinales están kilométricamente separados (Delirio: 126).

Se va del sitio específico -El Polo Club, el Cementerio Central, el Liceo Masculino, Unicentro, Torres de Salmona, Parque de La Independencia, Guadalupe- a la ciudad como tal -Las Lomas, Teusaquillo, La Cabrera-, a la composición departamental del país -Sasaima, Ibagué, Medellín-, hasta terminar con el mundo: Estados Unidos y México, Alemania y Francia, como el espacio perdido y anhelado desde un presente caracterizado por el horror de la violencia. De hecho, las historias que convergen en la Historia de la novela "se organizan como sistema de imágenes para representar el mundo, para explicar los temores del hombre frente a los misterios de la vida, que le dan validez al orden social o guía al individuo a través de sus crisis" (PinedaBotero, 1994: 26).

\section{La mujer que sabía demasiado o la negación de la vida desde la voz del otro}

La novela de Silvia Galvis² cuenta cómo el Estado hace todo lo posible, incluso cometer un crimen, para ocultar lo que todo el mundo sabe, pero que se representa en una sola mujer, la que sabía demasiado. El asesinato es la punta de iceberg de un momento en la historia real y actual de Colombia, cuando en medio del Proceso 8000, todo el país se dio perfecta cuenta de que el narcotráfico se incluyó en la política, no de la manera directa en la que en su momento lo hizo Pablo Escobar, sino la forma soterrada como los políticos empiezan a financiar sus campañas con dineros del narcotráfico, mientras en la plaza pública se condena a propios y extraños por aceptar dichos nexos.

Silvia Galvis (re)presenta una de tantas escenas que narrada desde la historia viene a recordar el instante real en que el dinero del narcotráfico impregnó la cara visible y suprema del poder Ejecutivo del país. Y desde la figura de Elizabeth Montoya de Sarria, conocida como "La monita retrechera",

\footnotetext{
2 Silvia Galvis también es autora de las novelas iViva Cristo rey! (1991), Sabor a mí (1995), Soledad, conspiraciones y suspiros (2002), Un mal asunto (2009); y de la obra de teatro De la caída de un ángel puro por culpa de un beso apasionado (1997), además de textos periodísticos y de entrevistas.
} 
-Diana Barragán de Saldarriaga, en la novela- atrapa la memoria colectiva que poco a poco fue olvidando las denuncias que presuntamente se conocían acerca de la infiltración de dineros "calientes" no solo en campañas políticas, sino en el sostenimiento económico de los partidos políticos. Mientras le corresponde a uno de los fiscales y su esposa ser la sana conciencia del poder Judicial.

La muerte como suceso que origina la novela se ve en el primer párrafo, y a partir de allí nos recrea las peripecias de Bruno Nolano y Sara Rosamunda Montiel por descubrir a los asesinos de Diana Barragán - pues al parecer tenía pruebas que relacionaban al Señor Presidente (sin nombre en la novela) con el Narcotráfico-, quienes se presentan en el segundo párrafo de la novela, al lector le corresponde seguir la investigación para ver cómo se enlaza con los posibles autores intelectuales del crimen: el exesposo de la víctima -famoso narcotraficante y encarcelado- o los que protegen al mandatario y sus ministros, ya que las pruebas son contundentes en la implicación del Jefe de Estado. La novela se resuelve con otro asesinato: el del fiscal y su esposa, a manos del mismo sicario de la primera muerte. Lo interesante es la voz que cuenta la historia, pues si bien el fiscal tenía la intención de escribir una novela negra, género del que era asiduo lector, su muerte le impide escribirla, y será otra voz la que permita su existencia como personaje y lo instaure en las redes del discurso (Bustillo, 1995: 48).

Asimismo, el ejercicio de escritura que está realizando el personaje le permite atar cabos sueltos en la investigación y resolver el caso, a la vez que le facilita a la autora iniciar el final de la narración, pues si se acaba la investigación es posible que se dé punto final a la novela, que de hecho termina con la muerte de los protagonistas. En este caso vemos que la intención de escritura del fiscal Nolano como metatexto lo integra al acto real de escritura hecho por Galvis como muestra de la dificultad que le acaece al autor al momento de escribir y que transmite a través de sus personajes, quizás porque estas dificultades "muchas veces va[n] en detrimento de los vuelos de la fabulación, encerrándose en las paredes de un espejo [el texto] que no por repetirse alcanza verdadera profundidad" (Bustillo, 1997: 171), pero que Galvis sí logra a partir de la presentación que hace del suceso histórico como hecho literario y un mecanismo para negar el olvido al que está acostumbrada la memoria del país, donde "lo que hoy parece grave, mañana nadie lo recuerda" ( $L M S D: 86)$, esta sería la respuesta a la pregunta: "¿Para qué diablos quiere uno escribir novelas en Colombia, si aquí la realidad supera la imaginación más truculenta?" (LMSD: 220), sentencia final de Nolano antes del posible viaje a los llanos orientales.

El espectro del país se extiende hasta Estados Unidos pasando por Cuba como ruta (re)conocida del narcotráfico en la novela. De hecho, el papel de Estados Unidos en el tema del tráfico de drogas aun no es claro, pues su intervención en el país con el denominado Plan Colombia, no es más que la forma cómo entre Estados se legitima el dinero del narcotráfico, pues todo comienza cuando el Congreso norteamericano aprueba la "ayuda para Colombia", con la que el gobierno colombiano combate el crimen organizado, decomisa millones de pesos, dólares y dinero en otras denominaciones, y sin importar el origen geográfico lo retorna al gobierno norteamericano como 
resultado del Plan Colombia. De hecho, en la novela por parte de la DEA se denomina a Colombia como una narcodemocracia, mientras en algunos momentos del siglo XX se habla, desde la prensa gringa, de Colombia como la democracia más sólida de América Latina, olvidando que todo lo sólido se desvanece en el aire. No es gratuito que en la novela sea necesario "contar los hechos antes de que [ ] la historia se hiciera humo en la memoria de la gente" (LMSD: 208).

Las fuentes periodísticas (prensa, televisión y radio), el hecho real del Proceso 8000, el asesinato de "La monita retrechera" y el grado de ficción en la escritura de Silvia Galvis son la sumatoria de elementos narrativos/narratológicos que permite instaurar en el lector la capacidad para reconocerse como partícipe en una historia que lo determina como sujeto histórico desde lo político, lo social, lo económico, lo cultural, lo religioso y lo particular. De hecho, el sincretismo de estos aspectos supone de por sí una forma de reconocimiento de lo colombiano desde lo local, lo regional (latinoamericano), lo global (Norteamérica y el Mundo), pues el estigma hacia el colombiano instaura una nueva forma de ver el país.

Diana Barragan (en la novela de S. Galvis), el Midas McAlister (de Delirio), Jaimison Ocampo (en la novela de Ma. Cristina Restrepo) y la Flaca (en la novela de P. Quintana) son ejemplo de cómo el arribismo se toma la clase alta y de dirección del país; mientras Diana, la Flaca y Jaimison provenían de la clase humilde del país, Midas tiene su origen en la clase media. Los dos comparten el deseo de tener dinero y clase social y para lograrlo harán lo que sea necesario: establecerse como puente de contacto entre el dinero del narcotráfico que financia la política por medio de empresarios, o el hacer de los residuos de la riqueza colombiana un dinero en "resurrección" entendida como multiplicación mediante el lavado de dinero. La fisura social que presentan las clases permite que se acceda a ellas sin ningún reparo.

\section{Coleccionistas de polvos raros, la joven y turbia mirada de la sexualidad}

La novela de Pilar Quintana ${ }^{3}$ hace el inventario de una juventud incapaz de evitar sucumbir ante la posibilidad de empezar a existir en una sociedad caracterizada por el anonimato de la pobreza. De hecho, los personajes de la novela, desde La Flaca hasta El Mono y demás, permiten imprimirle al texto un determinismo narrativo causado por las circunstancias de la historia que les correspondió vivir como generación. Un grupo de jóvenes estupefactos por lo que podría entenderse como la razón de su existencia, a pesar de que el futuro no se fraguara como una posibilidad, sino como el mantenimiento de un statu quo. Al final, el telón cae y la obra se montará en otro escenario.

Coleccionistas de polvos raros, es la gran evocación de un tiempo aciago en el que convergen dos horas específicas, las 9: 45 y las 11: 45, de una

3 Pilar Quintana es autora además de las novelas Cosquillas en la lengua (2003), Conspiración
iguana (2009), La perra (2017); y del libro de cuentos Caperucita se come al lobo (2012). 
noche, convertidas en las dos partes que componen la novela cuyo tiempo narrativo abarca "un presente, que seguimos y seguiremos llamando jueves por razones prácticas y poéticas, aunque sea viernes" (Coleccionistas...: 187). Rasgo que en la escritura nos permite reconocer una ciudad-temporal que ofrece una "extraordinaria cantidad de matices de comportamiento, numerosas contradicciones, y que en muchos ejemplos de la historia literaria la ciudad constituye en sí misma [la] trama central" (Merino, 2004: 136), como en el caso de la novela de Quintana. Espacio ideal para que la cultura asuma sus nuevas manifestaciones y dé equilibrio a una sociedad, que trata de insertarse en la historia ciudadana, y que anhela ser parte del otro como forma para identificar su propio origen desde el lugar que comparten: en la primera parte, nos encontramos con el bar como punto de giro de la ciudad (Coleccionistas... : 35); y en la segunda parte, el burdel (158-159). Espacios sociales que permiten identificar a los coleccionistas de polvos raros: la Flaca, Manuela Fernández Cuartas, quien se dedica a la prostitución (16) como voz regente de la novela, y que termina por ser la mantenida de Alguien (39), es quien "colecciona polvos por falta de voluntad" (67); y el Estrada menor (166) y su incesante búsqueda de aquel(la) que le genera dudas acerca de la masculinidad natural, y la pública iniciación sexual de su hermano mayor.

Esta armonía espacial está determinada por la presencia/ausencia de personajes ficticios y reales. Los primeros ligan la narración entre sí para caracterizar el escenario de la novela; y los segundos, solo son mencionados como parte del gran tablado en que se convirtió el país, y cuya presencia histórica le da el grado de realidad temporal que necesita la novela: los períodos presidenciales de César Gaviria (1990-1994) y Ernesto Samper (1994-1998), de este último se evoca en la novela el tan sonado Proceso 8.000 y del que da cuenta, con su propio estilo Silvia Galvis, estableciendo la relación tácita/implícita entre narcotráfico y política (Coleccionistas...: 223) mediante el testaferrato (clubes deportivos -127-, droguerías -162-, agencias de publicidad -127, 132-, emisoras de radio, 149), así como el lavado de dinero (realizando espectáculos populares -201-, utilizando almacenes de telas $-132-)$, etcétera.

Como parte del equilibrio en la ciudad están las dos visiones de la misma: la mía y la del otro como expresiones de un situs convertido en un habitus que se comparte y que en apariencia crea un problema, pues "lo que estamos presenciando no es tanto un conflicto de culturas cuanto la creación de un nuevo (y potencialmente unitario) tipo de sensibilidad" (Sontag, 1996: 380) que comparten las autoras; e incluso, el de una nueva estética: literaria, pictórica, cinematográfica, televisiva, musical, etc. De hecho, en la novela de Quintana la primera parte enfatiza en la posibilidad que tuvo la sociedad colombiana de escoger $(16,18,19,108-109)$ entre aceptar o negar el fenómeno del narcotráfico; y en la segunda parte, se establecen cinco reglas $(140,154,196,210,237)$ que determinarían la reconstrucción de la memoria para encontrar y explicar "el misterio de todo lo que pasó antes y después" (15) y que es la causa/efecto de la narración: "La noche terrible en que las inocencias se ensuciaron y los destinos se rompieron" (219), razón de más para que la Flaca sea quien limpie "la suciedad antes de que llegara a producirse para que todos pudieran retomar sus destinos donde los dejaron 
truncos" (219), pues en la ciudad solo quedaron personajes con aires de gran capo (porque no lo es) como John Wilmar (17-18), al malandro le tocó volver a ser atracador (232), en fin, la vida sigue, pues "la dignidad no la hemos perdido" (234).

Y quedan como "signos en perspectiva" del pasado continuo: el traqueto, la prepago y el sicario como personajes novelados. La figura del traqueto se asume como una bizarra visión de quien no alcanzó a ser capo, pues esa figura tiene un solo nombre y apellido, y por ello llama la atención con su estrafalaria vestimenta, los lujos que exhibe, el esquema de seguridad que le cuida y el grupo de mujeres, de las que hablaremos en el siguiente párrafo. El traqueto se alimenta del asombro de los demás, sean conocidos o no, pues en un comienzo su existencia/presencia llamó la atención, primero porque se mudaron a los espacios urbanos de los que tenían riqueza, él la ostentaba, compraban bienes raíces pagando en efectivo, tenían lujos que mostrar y fiestas que realizar, de hasta semanas enteras e incluso meses; luego se fueron relacionando en la medida en que no eran personajes ajenos a la sociedad cercana, se introdujeron en los círculos sociales ayudados por el dinero; para terminar, legalizaron su fortuna mediante negocios que de una u otra manera el Estado termina por legitimar; de hecho, en la novela de Pilar Quintaba, Don Chepe ordena construir un Club Colombia para él solo, pues en el de la clase pudiente de la ciudad de Cali no lo dejan entrar, no solo por ser un hijo de cualquiera, es decir, por no tener apellido, sino porque además en el formulario de afiliación al club colocó en la casilla profesión: "Traficante de drogas, a su servicio" (42).

La representación de la prepago se reconoce como la última versión de la prostitución, todo porque, como bien lo dijimos ya, el traqueto se hacía acompañar de varias jovencitas para amenizar no solo las fiestas que organizaba, sino sus traiciones. Múltiples historias se han desarrollado en torno a estas figuras, que en un momento fueron privadas, pero que luego en dos momentos bien referenciados por la prensa colombiana: uno en la ciudad de Medellín y otro en la ciudad de Giradot (cercana a Bogotá, y muy visitada por estos personajes, por ser de clima cálido), en las que se encuentran con el hallazgo macabro de los cadáveres de varias jovencitas. La investigación lleva a reconocer a un grupo de mujeres dedicadas a la prostitución exclusiva con narcos, quienes sin más ni más ofrecen elevadas sumas de dinero por sus servicios y con el que ellas logran "un ascenso social" en los barrios donde habitan". Para el caso de la novela de Quintana, está la figura de Estrellita, a quien no le importa la pregunta: "¿Le parece a la hija que ser la moza de un mafioso cuando podría ser una mujer independiente y profesional es escoger lo mejor?" (80).

\footnotetext{
4 La más famosa de las sagas acerca del tema son las novelas de Gustavo Bolívar M. Sin tetas no hay paraíso (2005) y Sin tetas sí hay paraíso (2015), a la que, de seguro, le sigue una tercera parte (y final), además de las novelas, con la primera se realizó una película, y una serie de televisión con cada una de las dos partes; asimismo, están las novelas Confesiones de una puta cara (2007) de Francisco Celis A., y Lo que fui y lo que soy (2011) de Marcela Loaiza. La novela de Celis aborda el tema desde la política, el narcotráfico y el paramilitarismo desde lo testimonial; y por su parte, Loaiza lo hace desde lo autobiográfico en una ciudad que como Pereira tiene su propia imagen mítica dentro de las urbes colombianas.
} 
El tríptico narco se complementa con el sicario, quizás la figura más representativa del narcotráfico, no solo por la literatura, sino por la vida real que vivió el país desde que la figura apareció por primera vez y de lejos, es decir, como un elemento aislado, en las novelas de Juan José Hoyos Tuyo es mi corazón (1984) y El cielo que perdimos (1990), y en medio de las dos, la presencia directa y sin miramiento de El Sicario (1988) de Mario Bahamón D. (cuya víctima, en la novela, será el cardenal Arturo Ramírez Campuzano). Luego están una seguidilla de novelas en las que se recrea la tipología de sicarios que aparecieron, más allá de la realidad, en la literatura colombiana para el caso que nos ocupa, pero que se explica/argumenta su existencia desde múltiples miradas narrativas latinoamericanas, Carlos Fuentes y Elmer Mendoza, entre otros 5 .

\section{La mujer de los sueños rotos, la ilusión efímera entre el deseo y el decoro}

La novela de Ma. Cristina Restrepo ${ }^{6}$ diluye, gracias al narcoescenario, las fronteras de clase que han existido y persisten en la sociedad colombiana. En un momento de la historia en la que el niño pobre se enamora de la niña rica, infancia no reconocida como tal, sino como forma familiar de establecer la relación entre los personajes. El narcotráfico "facilitó" el ingreso de una gran parte de la sociedad sin dinero a una pequeña parte de la sociedad con dinero. ¿De qué forma se logra?, pues con la tenencia de una nueva fortuna, ya que el dinero, ahora en abundancia, recorre todas las clases sociales, genera una nueva economía e imprime nuevas formas de ser a los sujetos, a pesar del rechazo, de labios para afuera, de este tipo de arribismo social, pues con el paso del tiempo, ya en la vida real, todos terminan aceptando al vecino traqueto que antes producía rechazo, pero que ahora, con su dinero, genera una nueva sombra: una nueva clase social.

María Cristina Restrepo nos ubica en Medellín -la ciudad perdida- e ilustra el contraste entre clases que vuelve a ser de interés narrativo: la protagonista pertenece a la clase pudiente de la ciudad y él, menos favorecido socialmente, hará hasta lo imposible para pertenecer a la gente que habita en El Poblado, pasa las tardes en el club, tiene piscina en sus fincas de descanso y lo logra, pues ya como capo ha logrado el poder económico que anhelaba, pero no puede ser socio del club, pues como Don Chepe, en la novela de Quintana: "lo rechazan por ser un hijo de cualquiera" (43). Y en este retrato de la sociedad medellinense están los

\footnotetext{
5 Al respecto del personaje del sicario en la novela colombiana es muy ilustrativo el trabajo La novela sicaresca. Testimonio, sensacionalismo y ficción (2009) de Margarita Jácome, quien hace un recorrido del tema para caracterizarlo, categorizarlo, tipificarlo, compararlo y analizarlo como ejercicio práctico de una literatura que da cuenta del estadio actual de la violencia en Colombia. En un espectro más amplio de la relación literatura y narcotráfico está en Solo las cruces quedaron (2013) de Ramón Gerónimo Olvera, quien en un copioso trabajo aborda el fenómeno literario desde los vectores: Colombia, México y España.

6 Ma. Cristina Restrepo es autora de las novelas Atardecer (1990), De una vez y para siempre (2000), Amores sin tregua (2006), El miedo, crónica de un cáncer (2010), Lo que nunca se sabrá (2011), Verás huir la calma (2014), Al otro lado del mar (2017), y del libro de cuentos La vieja casa de la calle Maracaibo (1989).
} 
sicarios, los negociantes, los traquetos, las prepagos y la gente tradicional de la ciudad que va viendo, sin querer, cómo los poderes van cambiando y quedan en un grupo que podría denominarse los "neorricos", pues son nuevos en todo: en el barrio, en la ciudad, en el club, en las discotecas, en la economía, en la política, en cualquier escenario que les permitiera asumirse con su nueva riqueza.

La novela de Ma. Cristina Restrepo comienza en el año 2000 e inmediatamente después, en el mismo capítulo (el 1) pasa a 1983, este salto extremo, tanto por lo rápido, como por el pasado que se hace presente continuo, es olvidado por el lector, gracias a que el viaje termina en un momento en que la historia real de la ciudad, a pesar del tono ficcional de la escritura, inunda de recuerdos el ejercicio de lectura: una sociedad tradicional que ha logrado una posición significativa gracias a su pasado; una ciudad que está desapareciendo ante el surgimiento de una nueva clase social; una mujer que anhelaba seguir con la tradición logrando con ello perpetuar el abolengo familiar que adquirió otrora tiempos más afortunados; y un ser particularmente elaborado por medio de la escritura para darle corporeidad y razón de ser en una búsqueda desenfrenada de ascenso social; es decir, es el "neorrico" del que hablamos en el párrafo anterior.

Al igual que en la otras novelas, asunto de este escrito, el escenario es la ciudad, en este caso Medellín, la ciudad de la eterna primavera, o la ciudad del Patrón, que de hecho y a estas alturas del escrito, apreciadas lectoras/apreciados lectores, tiene nombre y apellido propios, así que sigamos una ciudad anhelada por Laura Martínez, así como la anhela y extraña Fernando, el personaje de La virgen de los sicarios, pues ya no es la misma que se conoció o que se tuvo, en la lejana infancia; de hecho, la pérdida de esa seguridad que la tradición le daba a Laura, es la misma seguridad que la ciudad fue perdiendo, a medida que nuevos personajes vinieron a adornar la primavera, y a la vez, es cómo el país vio mermada su tranquilidad a causa de un fenómeno que se enquistó en una sociedad donde los valores se subvirtieron, pero se siguió manteniendo la apariencia, de tal forma que se atenuaran las consecuencias: "la mejor estrategia en esos casos era sostenerse en la mentira a pesar de que la evidencia dijera todo lo contrario, negar hasta lo más obvio, jugar con el deseo del otro de no creerse engañado, con el temor de enfrentar cambios inoportunos en la vida" (LMSR: 279).

Y en esa ciudad, como imágenes recuperadas de la memoria a través de la escritura van apareciendo, en sucinto inventario, personajes como Jamison Ocampo (o Pedro Luis Jaramillo, como signo de antioqueñidad), Laura Martínez, su esposo y sus hijos, además de su familia tradicional en cabeza del patriarca: el Dr. Martínez Tobón; El Gitano, El Patrón, Doña Nancy-Lou Díez de Mejía (que más abolengo que dicho nombre), Mory Francy y muchos más, que por razones de espacio no mencionaremos, pero que nos permiten reconocer la amalgama de relaciones que se establecen entre ellos sin que medie nada más que el dinero, que se adquirió honradamente (por tradición social) y el de los nuevos ricos (nuevos negociantes), aquellos que como Jamison Ocampo anhelaron siempre vivir en el barrio El Poblado de Medellín, en una ciudad cómplice, pues ayuda a cumplir los designios 
de la muerte, que también se pasea incólume por sus calles, en medio de la arquitectura de "los edificios que se adaptaban a las ondulaciones del terreno [dando un aire] de refinada intelectualidad" (LMSR: 99), y en contraste, la otra ciudad, la de la comuna trece de Medellín, en la que: "Las casas de la zona bordeaban un enjambre de calles que en la parte más alta se convertían en verdaderos laberintos de escaleras" (LMSR: 287).

El conflicto de clases presente en la novela y que acentuó el narcotráfico tiene sus antecedente en la gran brecha social que ha acompañado al país desde antes de sus inicios como república, de hecho la época republicana afianzó dichas diferencias, y que para subsanarse socialmente se han generalizado algunas formas de ascenso: el tener un terreno propio para construir una vivienda; luego aparece la opción de comprar una casa en una zona geográfica en la que vivan los ricos: el norte para Bogotá y el Sur para Medellín y Cali; años más tarde, tener un vehículo era signo de escalar socialmente; muchos años después fue la educación la forma en que los hijos lograban "limpiar" el apellido: estudian y van a la universidad, si es en una institución educativa de élite, bien, pero si es en una universidad extranjera, mejor; y finalmente, el narcotráfico no solo fracturó las diferencias entre clases, sino que instauró un nuevo nivel, que con el paso del tiempo se legitimó no solo por el Estado, sino por la sociedad en general. "Por eso es inútil discutir los recientes cambios en las relaciones familiares o pronosticar su desarrollo futuro sin tomar en cuenta los cambios económicos y sociales que han tenido lugar en los últimos años o la posible dirección que siga nuestra sociedad como un todo" (Rosenblatt, 2002: 177).

\section{Convergencias vectoriales}

Las cuatro novelas se ubican en un escenario en el que se reconocen que existen varias ciudades: la ciudad-bien y la ciudad-mal o la ciudad-otra, pues "su ciudad no es una sola, sino dos diferentes" (Coleccionistas...: 93), cada una con características propias, e incluso compartidas, pues "en esta ciudad bien el que no habla inglés es gente mal" (21), además tienen claro que "Ella está en el borde que separa los lados de la ciudad" (117). Esta razón lleva a que la coleccionista de polvos raros sienta que la ciudad ya no le pertenezca (35) y le permita reflexiones como: "en esta ciudad somos mamíferos pero civilizados" (38), "para pertenecer a la ciudad no basta con estar en ella" (39), "En esta ciudad hasta los muertos son perfectos" (56). De hecho, la estética de la violencia se reconoce por la forma en que se presentan las víctimas: cadáveres de exhibición en una muestra que más luego repercutirá en la plástica colombiana con sus propias expresiones, espectadores y mercado.

Asimismo, podemos hablar de ciudad-proceso, en la que se pasó "de retrete de estadio a mansión de pueblo" (54), pues una de tantas edificaciones fue levantada "con el solo propósito de que se notara la plata" (54), así fuera "una grosería arquitectónica" (54), todo porque es una ciudad trendy (230). En síntesis, esta ciudad-laberinto termina por descubrir su salida por medio de la escritura, ya que "en ella se recrea más que la sensibilidad de una generación de jóvenes de esta ciudad intermedia, el espíritu de una época en el ambiente juvenil" (Giraldo, 2004: 172). 
Las novelas del narcotráfico hasta ahora producidas cuentan con un escenario urbano, es la ciudad la que termina por habitar a los personajes y convertirse paulatinamente en ciudades literarias: como el espacio vectorial y geográfico en el que se desarrollan las historias de Laura Restrepo, Silvia Galvis (Bogotá); Pilar Quintana (Cali); y Ma. Cristina Restrepo (Medellín); momento propicio en el ritmo de la globalización que determina las miradas sobre nuevas geografías: las ciudades latinoamericanas y por conjunción además de las ciudades colombianas como epicentro de la mayor trama de historia desarrollada en este campo. Por su parte, el espacio rural está destinado a ser una etapa efímera de algunos personajes, sin que se llegue al protagonismo citadino, razón por demás para pensar en la negación de la periferia a partir de la implantación de la urbe cosmopolita. Esta es ya una ciudad criminal, pues "el crimen y la fuga veloz, vieja fórmula de la humanidad ahora a sus anchas desplegada en esta nueva geografía urbana, dedicada a saldar unas mil veces esa en abstracto vieja cuenta sin fondo de la sangre insaciable y sus rencores, fascinaciones de protagonismo anómico y de crueldad convertidas ahora en menú, televisivo, radiodifundido y profusamente impreso" (Cruz, 1998: 203).

En cuanto a la voz letrada en las novelas, esta se manifiesta a partir de un amplio panorama de referencias de lecturas que al ser inventariadas permiten ver cómo las escritoras asumen su rol desde la mirada activa de los personajes para nutrir desde sus propias lecturas lo que ve del mundo -entendido como la realidad-. En Pilar Quintana, no se hace citación alguna de textos o autores; sin embargo, aparecen un par de referencias musicales que permiten diferenciar la clase social según el gusto de la música que se escucha: el vallenato [Señora mía] (Coleccionistas...: 15-16) es el que prefiere la Protagonista; la música en inglés es escuchada por la gente bien de la ciudad: Pink Floyd (35-36, 172-175, 201); y Franco de Vita es música para mantecos (63-64).

En el caso de Laura Restrepo, en su novela convergen: José Saramago $(52,64)$, Pasolini $(54)$, León de Greiff $(76,77)$, Federico Chopin - George Sand (93), Jane Eyre (120), Ben-Hur y Mesala (135), Gabriel García Márquez (155), Humphrey Bogart (175), Pablo Neruda (179), Cenicienta (212), Ronsard (220), Byron (222), Bach - Shakespeare - Goethe (224). Presencias que se deben a Aguilar, quien es un profesor de literatura, en una universidad pública y que por estar en paro se dedica a vender comida para perros, y que es la voz inicial desde la que habla la autora. En cualquiera de los casos, las referencias en una u otra perspectiva se asumen como rasgo de separación social, distingo de características propias de un sujeto que busca su identidad a través de elementos externos y foráneos que le permiten justificar su existencia, su rol en el sistema narrativo de las novelas y por qué no, la última causa de su existencia, pues su voz se escucha, por sí sola o por el narrador que vislumbra el universo más allá del abismo de la palabra escrita.

En tanto, la novela de Silvia Galvis contiene un profuso inventario de referencias en torno al género negro/novela policiaca/novela de detectives, y a otros autores: S. Crafton (34); J. le Carré (57, 100, 189); Chandler, 
Chesterton, Highsmith, Dürrenmatt, Bradbury, Hammett, Fonseca (59); A. Fraser (60); G. G. Márquez (67); R. Fonseca (68); Victor Hugo (68); F. Durrenmatt (80, 110); A. Muñoz Molina (102); F. Peregil (102); J. Elroy (103); R. Fonseca (138, 192); G. Simenon (160, 187); A. Christie (172); Borges (185); T. Capote (186); Hesse (191); H. Miller (193); y Stendhal (227). Libros y autores que le sirven al protagonista de la novela para identificar técnicas, tácticas y estrategias en la resolución de casos, y ampliar el panorama de posibilidades en cuanto a su propio ejercicio de escritura, que, si bien no se lleva a cabo, termina por darle luces en cuanto a la resolución del "monicidio", término con el que se refiere al asesinato de Diana Barragán.

Otro elemento concomitante es el religioso, en Delirio conviven por gusto social/cultural el catolicismo tradicional con otras manifestaciones de credos y saberes; un diálogo entre lo occidental y lo oriental, y en medio de las dos atmósferas están los ritos que lleva a cabo Agustina para salir de su locura. En la novela encontramos desde Occidente, a Dios (25), al Niño Dios (15), a las vírgenes de Fátima y de Lourdes (25), la Virgen María (30), de Guadalupe (55), de La Merced (309); así como a Cristo barroco (55) y redentor (137), Jesuscristo (191); y desde Oriente, encontramos: Io Zen (34), el Feng shui $(38,66,312,332)$, y el I Ching (142).

En la novela de Galvis, la combinación está dada con la presencia de los cubanos Félix Hernández y Calixto Armenta, quienes con la excusa de acompañar a Diana Barragán y su esposo por el camino del conocimiento de la magia negra, también estaban haciendo inteligencia por parte de los jefes del negocio en Cuba. Este momento de la narración se desarrolla varias veces en la novela, pero entre las páginas 114 y 118 se hace un recuento de Oricha mayor (que personifica la sabiduría y aconseja mantenerse ocultos a la vista de ojos perversos, además puede influir y cambiar el destino más adverso, es un gran médico y uno de los dueños de los cuatro vientos), Osogbós (enviados por Echú), Changó (le proporcionó a Orulá el até -el tablero de Ifá-), Ifá (domina los secretos de la adivinación), Obatalá y Yemú (se les debe imitar, pues se profesan amor eterno), la trinidad Orulá, Odún y Olú (aconseja dónde buscar algo).

En cuanto a la novela de Quintana, Estelita, la madre de la Flaca, ahora es mística, espiritual, cósmica, esotérica (102), así que profesa aspectos como: "no hay mejor alimentos para el alma que darse a los otros" (104), se habla de almas gemelas, de vidas pasadas y regresión hipnótica (104), para terminar siendo naturista, encontrándose consigo misma y neutralizando la fuente de sus sufrimientos (105), así como alcanzando la serenidad cercana al nirvana y logrando incluso la sanación de malas energías con su voz melodiosa en el teléfono (106).

Desde La virgen de los sicarios (1994) de Fernando Vallejo, pasando por Rosario Tijeras (1999) de Jorge Franco, hasta llegar a Polvo eres y en polvo te convertirás (2012), de Roy Barreras, el elemento religioso forma parte explícita e implícita de las novelas del narcotráfico, más cuando las imágenes religiosas vienen a complementar la personalidad de Pedro Luis, 
que tenía que acordarse de "ponerse el escapulario, no el de oro, que no valía nada precisamente por ser tan caro, a quien se le ocurría ponerse un escapulario de oro macizo, sino el de la Virgen del Carmen, que llevaba a la cintura" (LMSR: 173), y en contraste, salvar la vida en aquellos tiempos violentos en Medellín, de seguro era gracias a: "la intervención milagrosa de la Virgen de la Gruta [ ] una imagen de tamaño natural olvidada durante años en una gruta incrustada en una curva de la carretera, [... y que...] se mantuvo medio olvidada hasta que Medellín cambió" (120).

No se puede hablar de narcotráfico sin hablar de la intervención estadounidense en el país y en la literatura, donde tiene tintes particulares que permiten establecer conexiones entre los textos, no exentos de realidad: "Si el Rony Silver se aguantaba mis desplantes era porque a través de mí le llegaba la mordida y estos de la DEA son más podridos que cualquiera" (Delirio: 43) acierta a decir Restrepo en su novela; además da cuenta de la "trinidad de la ley" que se "encargó" de Pablo Escobar (119); a la par se muestra el rótulo del país en el exterior: "El jefe de la DEA tiene razón, Colombia es una narcodemocracia gobernada por el narcogobierno ${ }^{7}$ más corrompido del plantea" (99) como lo manifiesta Sara R., el personaje de Galvis; también está Uriel Posada Meneses, esposo de Estela Ruán, fuente de información para acabar con Diana Barragán y a quien "la DEA lo tiene en la mira" (215) por sus vínculos con el narcotráfico. En un grado más cercano el papá de la Flaca, en la novela de Quintana, "era agente de la DEA" que luego despareció en el Guaviare (46-47).

En relación con la subcultura del sicariato, que ha dado tema para textos desde múltiples disciplinas, también es pertinente identificar aquello que tiene que ver con la negación nominal del sujeto, o podría decirse, de la nueva denominación del individuo, o de la renominación de la persona, esto, para hablar de los llamados "alias", entendiéndose como sinónimo de "apodo", "sobrenombre", "de otro modo", etc., sin embargo, en el mundo del crimen el uso de estos apelativos tiene que ver con el ocultamiento de la identidad, ruptura con el estatus establecido socialmente, de tal suerte que la proliferación de estos "alias" terminan nutriendo la imaginación de quienes socialmente denominan a estos personajes como: Pilatos, Escorpión, Drácula, Pollo Frito y Cotorra, que en la novela de Galvis son los sicarios; la Flaca -así la denominan de cariño sus nuevos amigos en la clase social a la que ahora pertenece-, el Patrón y el Mono -por el poder que ostentan y la clase a la que pertenecen-, en la novela de Quintana; y en la novela de Restrepo: el Midas McAlister, el paraco Ayerbe, la Araña Salazar, el Rony Silver -se han convertido ya en personajes insertados en esa "nueva clase social" que demostró "qué pobres son los ricos de este país" (82)-, también están Paco

\footnotetext{
7 La existencia de un narcoestado, como posibilidad, es narrada con tintes futuristas por Gonzalo Mallarino en su novela Año 2001: Romance en la narcoguerra (1990), la que es una historia de amor y de salvación del país en medio de una guerra que busca el restablecimiento de la democracia a manos de un grupo de intelectuales que lideran un movimiento civil del orden nacional y así salvar lo que queda de una república polarizada y cuya capital se divide en solo dos puntos cardinales: el norte y el sur, teniendo a la Calle 26 (Avenida El Dorado) como línea fronteriza.
} 
Malo y El Chupo -escoltas de la Araña-, y por último El Bichi -hermano menor de Agustina- que por su comportamiento es visto como un "bicho raro" minimizado. Vemos cómo se pasa del alias criminal a los apelativos por familiaridad o confianza8.

\section{A modo de conclusión}

He aquí cuatro escritoras que pertenecen al grupo de novelistas que con voz propia generan resonancias literarias de las voces colombianas en un mundo que intenta a pasos agigantados convertir la globalización en la negación de los espacios construidos desde lo histórico, lo literario y lo sociológico, más que desde lo económico. En este sentido, su aporte a la literatura colombiana "ha sido la presentación de una realidad histórica y social, tratada desde una óptica alternativa, particular y alejada de la oficial, en la que han puesto patas arriba la mayor parte de las creencias tradicionales sobre las estructuras de poder en Colombia" (Capote, 101).

La ciudad como situs, habitus y topos se elabora en la escritura desde lo histórico, lo literario, lo sociológico, lo económico y lo político; de hecho, la geografía del territorio facilita no solo la propagación de los cultivos ilícitos, sino que además fortalece el contrabando, situación que otrora tiempos permitía sostener la economía de un país en (con)formación. Situación ideal para adueñarse de las rutas del contrabando y convertirlas poco a poco en rutas del narcotráfico. Hecho que con el paso del tiempo se convierte en un estilo de vida habitual y común cuando se trata de aceptar, por la fuerza o no, la presencia en las ciudades de una nueva clase social fuerte económicamente, pero débil políticamente hablando. De hecho, el fin del "capo de todos los capos" comienza cuando decide ingresar a la política, terreno más peligroso, por los intereses que se manejan y la forma en que se subsanan los resentimientos, que el del propio mundo narco.

La narcocultura se convierte en un estilo de vida que empieza a determinar las sociedades, desde lo individual hasta lo colectivo, escenario propicio para que la voz autónoma de las escritoras colombianas suene y resuene en el ámbito local, regional, nacional y global. La literatura como ejercicio de expiación de un mal que empezó a aquejar a una sociedad marcada por la diferencia social, con un abismo enorme entre clases, con una desigualdad que raya en la malquerencia por no reconocer que el otro puede ser capaz de existir sin necesidad del uno, parece un escenario nada favorable para una nación que intenta encontrar su propio camino en Latinoamérica; sin embargo, las voces de Laura Restrepo, Silvia Galvis, Pilar Quintana y Ma. Cristina Restrepo ayudan a evitar la "amnesia selectiva" de la sociedad colombiana, pues está acostumbrada no solo a La Violencia, que se hizo visible con el

\footnotetext{
8 De hecho, el grado de familiaridad está determinado por el carácter subjetivo que tiene la mirada hacia el sujeto que se sale de lo cotidiano para así mortificar la razón de la verdad alterada por la ficción; en ese sentido es válida la subjetividad, a pesar de lo defectuosa que sea, pues termina siendo un lente neutro que registra todo lo que pasa (Báez-Silva, 2011: 185) y, en esta medida, la palabra se encuentra al servicio de la realidad ficcionalizada desde la postura, no neutra, de la escritura/la escritora.
} 
asesinato de Jorge Eliécer Gaitán, y que alcanzó un estado superior con el advenimiento del narcotráfico, sino que además se acostumbró a olvidarse rápidamente del dolor histórico que dicho fenómeno causó y que nos está aplazando la segunda oportunidad sobre la tierra.

\section{Obras citadas}

Báez-Silva, Ángela Ma. "Una excursión a los indios ranqueles. Un puente para no cruzar". Libro abierto. Los estudios literarios y su encuentro con otras disciplinas. Comp. Paola A. Uparela R. Bogotá: Universidad de los Andes, 2011.173-190.

Bahamón Dussán, Mario. El sicario. Cali: Orquidea, 1988. Impreso.

Blanco, Juan Alberto. "La orfandad -herencia- social". El universo narrativo de Laura Restrepo. Eds. Elvira Sánchez-Blake y Juliet Lirot. Bogotá: Taurus, 2007. 293-310. Impreso.

Bolívar, Gustavo. Sin tetas no hay paraíso. Bogotá: Quintero, 2005. Impreso. Sin tetas sí hay paraíso. Bogotá: Planeta, 2015. Impreso.

Bustillo, Carmen. El ente de papel. Un estudio del personaje en la narrativa latinoamericana. Caracas: Vadel Hermanos, 1995. Impreso. La aventura metaficcional. Caracas: Equinoccio, 1997. Impreso.

Capote D., Virginia. "Historia, mujeres y ficción: la herencia literaria de Silvia Galvis". Estudios Colombianos (2011): 97-102. Impreso.

Celis Albán, Francisco. Confesiones de una puta cara. Bogotá: Intermedio, 2007. Impreso.

Chiampi, Irlemar. El realismo maravilloso. Caracas: Monte Ávila, 1983. Impreso.

Cruz Kronfly, Fernando. La tierra que atardece. Ensayos sobre modernidad y contemporaneidad. Bogotá: Ariel, 1998. Impreso.

Galvis, Silvia. La mujer que sabía demasiado. Bogotá: Planeta, 2006. Impreso.

Giraldo, Luz Mary. Ciudades escritas. Bogotá: Convenio Andrés Bello, 2004. Impreso.

Hoyos, Juan José. Tuyo es mi corazón. Bogotá: Planeta, 1984. Impreso. . El cielo que perdimos. Bogotá: Planeta, 1990. Impreso.

Jácome, Margarita. La novela sicaresca. Testimonio, sensacionalismo y ficción. Medellín: EAFIT, 2009. Impreso.

Loaiza, Marcela. Lo que fui y lo que soy. Bogotá: Planeta, 2011. Impreso.

Mallarino, Gonzalo. Año 2001: Romance en la narcoguerra. Bogotá: Oveja Negra, 1990. Impreso.

Olvera, Ramón Gerónimo. Solo las cruces quedaron. México: Ficticia, 2013. Impreso.

Pineda-Botero, Álvaro. Del mito a la posmodernidad. La novela colombiana de finales del siglo XX. Bogotá: Tercer Mundo, 1994. Impreso.

Quintana, Pilar. Coleccionistas de polvos raros. Bogotá: Norma, 2007. Impreso.

Llovet, Jordi, et al. Teoría literaria y literatura comparada. Madrid: Ariel, 2005. Impreso.

Mejía Quintana, Oscar. Sociedades complejas, modernidades y globalización. Bogotá: Universidad Nacional, 2009. Impreso.

Merino, José Ma. Ficción continua. Madrid: Seix Barral, 2004. Impreso.

Restrepo, Laura. Delirio. Bogotá: Alfaguara, 2004. Impreso. 
Restrepo, Ma. Cristina. La mujer de los sueños rotos. Bogotá: Seix Barral, 2009. Impreso.

Rosenblatt, Louise M. La literatura como exploración. México: FCE, 2002. Impreso.

Sontag, Susan. Contra la interpretación. Madrid: Alfaguara, 1996. Impreso. . Cuestión de énfasis. Bogotá: Alfaguara, 2007. Impreso. 
